Saudi Journal of Humanities and Social Sciences

Abbreviated Key Title: Saudi J Humanities Soc Sci

ISSN 2415-6256 (Print) | ISSN 2415-6248 (Online)

Scholars Middle East Publishers, Dubai, United Arab Emirates

Journal homepage: https://saudijournals.com

Original Research Article

\title{
Knowledge of Hypertension among Nurses at a Tertiary Medical College Hospital, Sylhet
}

\author{
Mahbuba Akter ${ }^{1 *}$, Md. Abdul Hadi Suhag ${ }^{2}$ \\ ${ }^{1}$ Nursing Instructor, Enam Nursing College, Savar, Dhaka, Bangladesh \\ ${ }^{2}$ Lecturer, CRP Nursing College, Savar, Dhaka, Bangladesh
}

\begin{abstract}
DOI: $\underline{10.36348 / \text { sihss.2020.v05i12.005 }}$
| Received: 28.11.2020 | Accepted: 05.12.2020 | Published: 20.12.2020
\end{abstract}

*Corresponding author: Mahbuba Akter

\section{Abstract}

This cross-sectional study was performed among 150 senior staff nurses of Sylhet MAG Osmani Medical College during from September to December 2019 to assess the knowledge of nurses about hypertension. The maximum age of the respondents was 51 years and the minimum age was 25 years. The maximum respondents $77(51.33 \%)$ were in $35-45$ age group. The prevalence of hypertension among the relatives of senior staff nurses was about 33\%. Of them $12 \%$ told that there was a history of hypertension among their mothers, $7.3 \%$ told the history of hypertension among their fathers, Sisters $3.3 \%$, Brothers $2.7 \%$ and uncles. The mean age of the respondents was $37.39 \pm 5.24$ years. The educational qualification revealed that the majority had SSC (74.7\%). and HSC, Degree and masters were $17.3 \%, 7.3 \%$ and .7\% respectively. The professional qualifications of the respondents found that $131(87 \%)$ were Diploma in nursing and Diploma in midwifery, $10.7 \%$ were BSC nursing and only $2 \%$ were MPH holders. The majority $98.7 \%$ were responded hypertension was genetic, only $1.3 \%$ told hypertension was not genetic. The majority $(81.3 \%)$ of the respondents told that it was a disease in blood vessel, $14.7 \%$ told it was a heart disease and only $3.3 \%$ told that it was a Brain disease. Knowledge on types of hypertension, $93.33 \%$ (n-150) told Primary \&Secondary hypertension, only $6.66 \%$ told all three types of hypertension. 99.3\% had knowledge about essential hypertension while only 7 had no knowledge about essential hypertension. Majority (49.33\%) of the respondents told Genetic, smoking, Diabetes, Smoking, Kidney disease, overweight, High intake of fat containing diet, physical inactivity, anxieties, excess salt intake, Drug addiction were the causes of hypertension. $48.66 \%$ told Genetic, smoking, Diabetes were the causes of Secondary HTN, 23.33\% anxieties, excess salt intake, Drug addiction. Problems of uncontrolled hypertension were showed that majority $93.3 \%$ of the respondents told headache, neck pain, vertigo, nausea, restlessness, chest compression were the problems caused by uncontrolled hypertension. 98.0\% told Genetic, smoking, Diabetes, anxieties, excess salt intake and overweight were the personal factors caused by HTN. Knowledge about the grade of hypertension was found that $95.33 \%$ told grade-1 and grade- 2 hypertension and only $4.66 \%$ had known all three types of hypertension. Results showed that $99.3 \%(n=149)$ had told exercise, control body weight, change food habit, medication and stop smoking were the control measures of HTN. $65.3 \%$ told containing diet, control HTN. Related diseases avoid anxieties, increase intake of vegetables and fruits were the preventive measures of HTN. The insignificant association was found between age of the respondents and knowledge about preventive measures of hypertension. ( $\mathrm{p}$ value> .05).

Keywords: Blood Pressure, Heart Attack, Knowledge of Hypertension, Nurses, Tertiary Level.

Copyright (C) 2020 The Author(s): This is an open-access article distributed under the terms of the Creative Commons Attribution 4.0 International License (CC BY-NC 4.0) which permits unrestricted use, distribution, and reproduction in any medium for non-commercial use provided the original author and source are credited.

\section{INTRODUCTION}

Hypertension (high BP) is a disease of vascular regulation in which the mechanisms that control arterial pressure within the normal range are altered. Predominant mechanisms of control are the central nervous system (CNS), the renal pressor system (renin-angiotensin-aldosterone system), and extracellular fluid volume. It has become a significant problem in many developing countries experiencing epidemiological transition from communicable to non communicable chronic diseases [1].

The emergence of hypertension and other CVD as a public health problem in these countries is strongly related to the aging of the populations, urbanization, and socioeconomic changes favoring sedentary habits, obesity, alcohol consumption, and salt intake, among others [2]. A cost-effective use of health services to control these emerging chronic diseases is 
particularly needed in developing countries because resources are limited and generally must be shared with the concurrent burden of persistent communicable diseases.

In this context, hypertension presents a major area of intervention because it is a frequent condition and is amenable to control through both non pharmacological lifestyle factors and pharmacological treatment. Pharmacological treatment for hypertension has been shown to be effective in decreasing BP and subsequently cardiovascular events [3], although BP levels achieved in treated patients may still be considerably higher than those in truly normotensive persons. Lifestyle measures for lowering BP include reduced alcohol intake, reduced sodium chloride intake, increased physical activity, and control of overweight [4]. Lifestyle interventions also have the potential to reduce the need for or the amount of medications in hypertensives and prevent high BP from developing in nonhypertensives. Furthermore, lifestylek interventions are instrumental in controlling other concomitant cardiovascular risk factors not necessarily related to hypertension, such as smoking, raised cholesterol level, or diabetes, hence the importance of a multifactorial approach to effective risk reduction in hypertensives[5].

Several models have been proposed to account for health behaviors and sustained behavioral changes. Although they may differ in content and perspective, models for behavior change stress the importance of evaluating the perceptions, attitudes, beliefs, and outcome expectations of individuals as a crucial means to understand observed behaviors and to guide behavioral change. A proper assessment and understanding of KAP factors are particularly helpful in the area of chronic conditions such as hypertension, for which prevention and control necessitate a lifelong adoption of healthy lifestyles [6].

In Seychelles (Indian Ocean), a middle-income country with a fairly high standard of health care, CVD currently accounts for $>30 \%$ of all deaths. Adjusted to the Segi's world population, the prevalence of hypertension $(\mathrm{BP} \geq 160 / 95 \mathrm{~mm} \mathrm{Hg}$ or taking antihypertensive medication) was $28 \%$ in men and $22 \%$ in women aged 25 to 64 years in a first population survey conducted in 1989. In 1991, a nationwide program was launched to reduce cardiovascular risk factor levels in the population. The program has been mostly targeting the general population and relies on extensive health education through the mass media, inclusion of a heart health education program in the primary school curriculum, and several regulatory measures. Interventions also targeted hypertensive individuals (high-risk strategy) and included, among others, hypertension screenings in public and work places and the organization of primary healthcare-based heart health clubs, whereby hypertensive patients are offered interactive teaching sessions on cardiovascular risk factor management [7].

Evidence of the benefit of antihypertensive treatment in people with high blood pressure is overwhelming. Effective treatment reduces risk of stroke by $40 \%$ and of any cardiovascular event by $25 \%$ [29]. The benefits are greater in elderly people because they have a higher absolute risk of cardiovascular disease. It is estimated that while 168 young and middle-aged people with hypertension would need to be treated for 5 years to save one major fatal or non-fatal cardiovascular event, only 46 patients aged $\geq 60$ years would need to be treated for the same benefit. Furthermore, research on isolated systolic hypertension in the elderly suggests that the number needed to treat for 5 years to prevent one major cardiovascular event in people aged $\geq 70$ years is less than 20 . Reducing high blood pressure is therefore highly cost effective. In the $\mathrm{UK}$, around half the population aged $>65$ years has high blood pressure (defined as blood pressure $\geq 160 / 95$ $\mathrm{mmHg}$ ), and 125000 people suffer a stroke each year at a cost of $£ 2.3$ billion to the NHS and Social Services. Most strokes are not fatal, and the major burden of stroke is chronic disability. Even a small reduction in incidence by improved blood pressure control would yield substantial cost savings. Most people with high blood pressure are managed in general practice. Unfortunately, quality of has major care is often inadequate. Since Tudor Hart's groundbreaking work in the 1970s, subsequent surveys have continued to show incomplete detection, treatment and control. Probably only about a quarter of hypertensive patients have their blood pressure adequately treated, and this implications for cardiovascular morbidity and mortality. For example, a large observational study from Merseyside of 6139 patients aged >65 years from 76 general practices found that only $64 \%$ of hypertensives were receiving treatment, of whom only $54 \%$ had a blood pressure of $<160 / 90 \mathrm{mmHg}$ (which is above current targets of 140/85 mmg). 1 In addition, little attention has been given to blood pressure management among people from lower socio-economic groups and those from ethnic minorities such as South Asians and people of African or Caribbean origin who have an increased risk of hypertension and diabetes. One UK primary care-based study found that although people of African origin were more likely to be on antihypertensive treatment, they were also more likely to have blood pressure levels above the guidelines. Interventions are needed to reduce such health inequalities [8].

In this study, we will examine Knowledge of senior staff nurses for hypertension and associated risk factors with or without known hypertension to help improve primary and secondary CVD prevention and control programs. Comparison of Knowledge between nurses aware of being hypertensive versus nurses unaware of being hypertensive (rather than between nurses with high versus low BP, for example) was made 
on the assumption that aware hypertensive was likely to have been exposed to more information, health care, and personal experience related to hypertension than persons nurses of being hypertensive. This distinction was also chosen to gather information that would be useful in shaping the usually different strategies targeting the population (mostly prevention) and the patients.

\section{Background of the Study}

A common disorder that is a known cardiovascular disease risk factor, characterized by elevated blood pressure over the normal values' of $120 / 80 \mathrm{~mm} \mathrm{Hg}$ in an adult over 18 years of age. This elevation in blood pressure can be divided into three classes of hypertension. Pre hypertension describes blood pressure measurements of greater than $120 \mathrm{~mm}$ $\mathrm{Hg}$ systolic or $80 \mathrm{~mm} \mathrm{Hg}$ diastolic and less than 130 $\mathrm{mm} \mathrm{Hg}$ systolic or $90 \mathrm{~mm} \mathrm{Hg}$ diastolic. Persons exhibiting pre hypertension are encouraged to explore life-style modifications to lower blood pressure, but blood-pressure lowering agents are not generally prescribed without compelling indications. The second classification of hypertension is Stage 1 hypertension and is defined by a blood pressure of over $130 \mathrm{~mm} \mathrm{Hg}$ systolic or $90 \mathrm{~mm} \mathrm{Hg}$ diastolic but less than $160 \mathrm{~mm}$ $\mathrm{Hg}$ systolic or $100 \mathrm{~mm} \mathrm{Hg}$ diastolic. Patients with Stage 1 hypertension are also encouraged to make life-style modifications, and initial drug therapy may include thiazide-type diuretics, ACE inhibitors, calcium channel blockers, beta blockers, and angiotensin-receptor blockers, or a combination of these. Stage 2 hypertension is defined by a blood pressure greater than $160 \mathrm{~mm} \mathrm{Hg}$ systolic or $100 \mathrm{~mm} \mathrm{Hg}$ diastolic. Persons with Stage 2 hypertension are encouraged to make lifestyle modifications. Two-drug combination therapies (of thiazide-type diuretics, ACE inhibitors, calcium channel blockers, beta blockers, and angiotensinreceptor blockers) are indicated for these patients.
Essential hypertension, the most common kind, has no single identifiable cause, but risk for the disorder is increased by obesity, a high serum sodium level, hypercholesterolemia, and a family history of high blood pressure. Known causes of secondary hypertension include sleep apnea, chronic kidney disease, primary aldosteronism, renovascular disease, chronic steroid therapy, Cushing's syndrome, pheochromocytoma, coarctation of the aorta, and thyroid or parathyroid disease. The incidence of hypertension is higher in men than in women and is twice as great in African-Americans as in Caucasians. People with mild or moderate hypertension may be asymptomatic or may experience suboccipital headaches, especially on rising; tinnitus; lightheadedness; ready fatigability; and palpitations. With sustained hypertension, arterial walls become thickened, inelastic, and resistant to blood flow, and the left ventricle becomes distended and hypertrophied as a result of its efforts to maintain normal circulation against the increased resistance. Inadequate blood supply to the coronary arteries may cause angina or myocardial infarction. Left ventricular hypertrophy may lead to congestive heart failure. Malignant hypertension, characterized by a diastolic pressure higher than $120 \mathrm{~mm} \mathrm{Hg}$, severe headaches, blurred vision, and confusion, may result in fatal uremia, myocardial infarction, congestive heart failure, or a cerebrovascular insult. Patients with high blood pressure are advised to follow a low-sodium, lowsaturated-fat diet; to control obesity by reducing caloric intake; to exercise; to avoid stress; and to have adequate rest. Hypertension (high BP) is a disease of vascular regulation in which the mechanisms that control arterial pressure within the normal range are altered. Predominant mechanisms of control are the central nervous system (CNS), the renal pressor system (reninangiotensin-aldosterone system), and extracellular fluid volume [9].

\section{Classification}

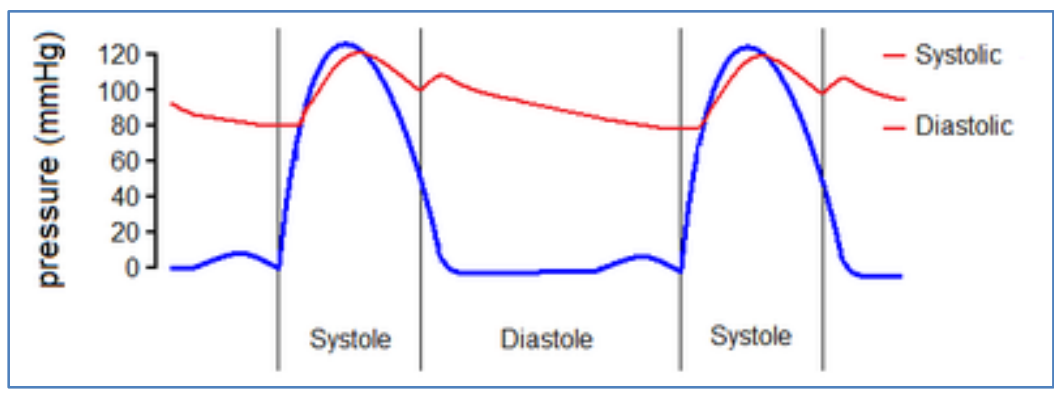

The variation in pressure in the left ventricle (blue line) and the aorta (red line) over two cardiac cycles (heart beats), showing the definitions of systolic and diastolic pressure.

A recent classification recommends blood pressure criteria for defining normal blood pressure, pre-hypertension, hypertension (stages I and II), and isolated systolic hypertension, which is a common occurrence among the elderly. These readings are based on the average of seated blood pressure readings that were properly measured during 2 or more office visits. In individuals older than 50 years, hypertension is considered to be present when a person's blood pressure is consistently at least $140 \mathrm{mmHg}$ systolic or $90 \mathrm{mmHg}$ diastolic. Patients with blood pressures over 130/80 mmHg along with Type 1 or Type 2 diabetes, or kidney disease require further treatment [10]. 


\begin{tabular}{|l|l|l|}
\hline Classification & $\begin{array}{l}\text { Systolic kPa }\left(\mathbf{k n} / \mathbf{m}^{2}\right) \\
\mathbf{m m H g}\end{array}$ & $\begin{array}{l}\text { Diastolic } \\
\mathbf{m m H g} \mathbf{~ k a}\left(\mathbf{k n} / \mathbf{m}^{2}\right)\end{array}$ \\
\hline Normal & $90-119,12-15.9$ & $60-79,8.0-10.5$ \\
\hline Pre-HTN & $120-139,16.12-18.5$ & $81-89,10.82-11.9$ \\
\hline Stage-1 & $140-159,18.72-21.2$ & $90-99,12-13.2$ \\
\hline Stage-2 & $>=160, \quad>=21.3$ & $>=100,>=13.3$ \\
\hline Isolated systolic HTN. & $>=140, \quad>=18.7$ & $<90,<12$ \\
\hline
\end{tabular}

It is also known that hypertension is highly heritable and polygenic (caused by more than one gene) and a few candidate genes have been postulated in the etiology of this condition [11].

\section{Causes}

Idiopathic Hyperactivity of sympathetic vaso constricting nerves Presence of vasoactive substance on smooth muscle Increased cardiac output, followed by arteriole constriction Excessive dietary sodium intake, sodium retention, insulin resistance, and hyperinsulinemia Familial (genetic) tendency

\section{Isolated Systolic Hypertension}

Systolic Bp Elevation in the Absence of Elevated Diastolic Bp Is Termed Isolated Systolic Hypertension

\section{Secondary Hypertension}

Secondary Hypertension Occurs in Approx. 5\% of Patients with Hypertension Renal Pathology: Congenital Anomalies, Pyelonephritis, Renal Artery Obstruction, Acute and Chronic Glomerulonephritis Reduced Blood Flow to Kidney Causes Release of Renin. Renin Reacts with Serum Protein in Liver Coarctation of Aorta Endocrine Disturbances: Pheochromocytoma Adrenal Cortex Tumors Cushing's Syndrome Hyperthyroidism Medications such as Estrogens, Sympathomimetics, Antidepressants, Nsaids, and Steroids

\section{Consequences of Hypertension}

Consequences of hypertension prolonged hypertension damages blood vessels in the brain, eyes, heart, and kidneys and increases the risk of stroke, angina, mi, blindness, and heart and kidney failure blood vessel damage occurs through arteriosclerosis in which smooth muscle cell proliferation, lipid infiltration, and calcium accumulation occur in the vascular epithelium damage to heart, brain, eyes, and kidneys is termed target organ disease; this is the major object of prevention in patients with high bp

\section{Risk Factors}

Risk Factors Increase in Incidence is Associated with the Following Risk Factors: - Age: Between 30 And 70 Race: - Black Overweight, Sleep Apnea Family History Smoking Sedentary Lifestyle Diabetes Mellitus Metabolic Syndrome

\section{Research Evidence}

Prevalence: Black -30\% Non-Hispanic Whites25\% Mexicans-Americans-22\% Recent Data Have Shown That Only $70 \%$ Of Adults with Hypertension Are Aware of It, 59\% Receive Treatment, And Only 34\% Reach Bp Control (Less Than 140/90 Mm Hg).

\section{Clinical Manifestations}

Usually Asymptomatic May Cause Headache, Dizziness, Blurred Vision When Greatly Elevated Bp Readings More Than 140/90 Mm of $\mathrm{Hg}$

\section{Diagnostic Evaluation}

Ecg Chest X-Ray Proteinuria, Elevated Serum Blood Urea Nitrogen (Bun), And Creatinine Levels Serum Potassium Urine (24-Hour) For Catecholamines Renal Scan Renal Duplex Imaging Outpatient Ambulatory Bp Measurements

\section{Management}

Lifestyle Modifications Lose Weight If Body Mass Index Is Greater Than or Equal To 25. Limit Alcohol Get Regular Aerobic Exercise Equivalent to 30 to 45 Minutes of Brisk Walking Most Days. Cut Sodium Intake To $2.4 \mathrm{G}$ or Less Per Day Include Recommended Daily Allowances of Potassium, Calcium, And Magnesium in Diet. Smoking Cessation Reduce Dietary Saturated Fat and Cholesterol Consider Reducing Coffee Intake If, Despite Lifestyle Changes, The Bp Remains at Or Above 140/90 Mm Hg Over 3 To 6 Months, Drug Therapy Should Be Initiated If Bp Extremely Elevated or In Presence of Cardiovascular Risk Factors, Single Drug Therapy May Be Given

\section{Considerations in Selecting Therapy}

Race: Blacks Respond Well To Diuretic Therapy; Whites Respond Well To Ace Inhibitors Age: - Some Adverse Effects May Not Be Tolerated Well By Elderly People Concomitant Diseases and Therapies: Some Agents Also Treat Migraines, Benign Prostatic Hyperplasia, Heart Failure Quality Of Life Impact: Tolerance of Adverse Effects Economic Considerations: - Newer Agents Very Expensive

\section{Anti-Hypertensive Drug Groups}

Diuretics Beta-Adrenergic Blockers AlphaReceptor Blockers Central Alpha Agonists Peripheral Adrenergic Agents Combined Alpha and BetaAdrenergic Blockers Ace Inhibitors Angiotensin Receptor Blockers Calcium Antagonists Direct Vasodilators 


\section{Best Management of Hypertension}

To Use the Fewest Drugs at The Lowest Doses While Encouraging. The Patient to Maintain Lifestyle Changes. After Bp Has Been Under Control For At Least 1 Year, A Slow, Progressive Decline in Drug Therapy Can Be Attempted. However, Most Patients Need to Resume Medication Within 1 Year.

\section{Patient Education Guidelines}

Following the DASH eating plan DASH Dietary Approaches to Stop Hypertension Based on 2,000 calories per day diet Depending on patient's caloric needs, the number of daily servings may vary.

\section{OBJECTIVE OF THE STUDY \\ General objective}

To assess the level of knowledge of nurses regarding hypertension in a tertiary level hospital, Sylhet

\section{Specific Objectives}

I. To assess knowledge about environmental risk factors of hypertension of the respondents.

II. To assess knowledge regarding personal factors of hypertension of the respondents

III. To assess knowledge about genetic factors of hypertension of the hypertension.

IV. iv. To assess knowledge about prevention and control of hypertension of the respondents.

V. To assess socio-economic status of the respondents

\section{Operational definitions}

Knowledge: Knowledge knows things, objects, events, persons, situations and everything in the universe. In addition, it is a clear and certain mental perception, understanding, aware of something, acquaintance or familiarity with information, and learning that which is known.

\section{Hypertension}

Elevation of the arterial blood pressure above the normal range expected in a particular age group. Irrespective of age, systolic blood pressure $\geq 140 \mathrm{mmHg}$ and diastolic blood pressure $\geq 90 \mathrm{mmHg}$ were considered as hypertension. The medical specialist confirmed it.

\section{Excess edible salt}

The sodium salt $(\mathrm{NaCl})$ used in foods for cooking and used as table salt is defined as edible salt. Intake of extra sodium salt during eating foods was considered as excess intake of edible salt.

\section{Heart failure}

It is a condition in which the pumping action of the ventricle of the heart is inadequate. Clinically, leg swelling and/or engorged neek veins were considered as heart failure.

\section{Heart attack}

It is a death of a segment of heart muscle, which follows interruption of its blood supply. History of myocardial infarction was included as a heart attack.

\section{Stroke}

It is a sudden attack of weakness and/or paralysis affecting one side of the body. It is the consequence of an interruption to the flow of blood to the brain. Positive history and treatment in a hospital was considered as stroke.

\section{Unconsciousness}

It is a condition of being unaware on one's surroundings. Positive history was included as unconsciousness.

\section{Cataract}

Any opacity in the lens of the eye that results in blurred vision is known as cataract. It may be congenital or due to metabolic diseases such as diabetes, direct or indirect injury to the lens, prolonged exposure of the eye to ultra-violet rays, chronic uncontrolled hypertension. Cataract due to positive history of chronic hypertension was included only.

\section{Anxiety}

It is the generalized pervasive fear that dominates or interfere the individual's daily activities and/or life. It may be specific or nonspecific. Nonspecific is known as generalized anxiety.

\section{Justification of the study}

World Health Organization (WHO) reported that hypertension and its consequences is the most common and leading cause of morbidity and mortality in the industrial world as well as becoming an increasing common disease in the developing countries. It is one of the 10 leading reported causes of death and about $4 \%$ death were due to hypertension complication in Bangladesh [13]. The top most risk factors for the development of future hypertension are increased intake of sodium salt, tobacco products use, obesity, elevated level of serum cholesterol, lack of physical exercise, excess stress and anxieties and positive genetic disposition, age or gender, but he/she can change or modify or avoid other risk factors. The risk factors which, which can be adjusted or modified through lifestyle advice, are sodium salt intake, tobacco product use, obesity, serum cholesterol level, physical exercise, stress and anxieties, unsatisfactory diet, unplanned urbanization and improper lifestyle functions[14].

The prevention of complications resulting from high blood pressure in population requires reducing the risk of developing high blood pressure in the population as a hole; and identifying individuals with high blood pressure who are at increased risk of developing complications. Hypertension in this context is used to denote all levels of elevated blood pressure 
associated with increased risk of complications and not only those in need of special antihypertensive treatment. The combination of the individual approach with the population approach, which seeks to control the causes of hypertension, provides a comprehensive strategy for prevention and control of hypertension. The justification of the individual approach is clear since both the risk of high blood pressure and the benefits of effective intervention to reduce it have been convincingly demonstrated over a wide range of high blood pressure. The greater the cumulative risk of cardiovascular events and other adverse out comes, the greater the benefit of effective blood pressure reduction and the greater the need for early and effective intervention.

The ultimate aim of this study is to decrease morbidity and mortality due to hypertension. It is a grave threat to the public health in Bangladesh. Because of, most of the risk factors are prevalent in Bangladesh. In addition, People living with hypertensions are the topmost high-risk subpopulations who become physically disabled all on a sudden. Therefore, assessment of knowledge of senior staff nurses on prevention and control of hypertension will be the vital important and public interest. The findings of the study will significantly be supportive and enhance the national prevention and control activities against hypertension.

\section{MATERIALS AND METHODS}

The research work was a descriptive type of cross-sectional study performed on the nurses of Sylhet MAG Osmani Medical College to assess the knowledge on hypertension and factors associated with it.

\section{Study population and sample}

The study populations were the nurses of Sylhet M.A.G Osmani Medical College Hospital. The research participants were recruited from study population consecutively on the basis of defined selection criteria.

\section{SELECTION CRITERIA \\ Inclusion criteria \\ - Senior staff nurse \\ - Voluntary participation}

\section{Exclusion Criteria \\ - Assistant nurse \\ - Unwilling to participate \\ - Mentally ill}

Place of study
Sylhet MAG Osmani Medical College
Hospital

\section{Study period}

The study was conducted from September to December 2019.

\section{Sample size}

Sample was too calculated by the following formula:

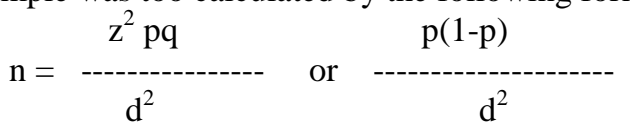

Where,

$\mathrm{n}=$ asking sample size

$\mathrm{z}=$ level of confidence or level of significance

$\mathrm{d}=$ Standard error

$\mathrm{p}=$ the proportion in the population possessing the

\section{Characteristic of interest}

The ' $p$ ' is the proportion of knowledge among the nurses having hypertension, which was evidently unknown. Since $\mathrm{p}=0.5$ in the formula yields the maximum value of ' $n$ ' and the sample was yield at least the designed accurateness. A 95\% confidence interval $(\mathrm{z}=1.96)$ with 0.05 standard error $(\mathrm{d}=0.05)$ was to be desired in this study. Hence, the sample size was as follows

$$
n=\frac{(1.96)^{2}(0.5)(0.5)}{(0.05)^{2}}
$$

There was limitations of time and others constrains sample size was limited to 150 in this study.

\section{Sampling technique} this study.

Purposive sampling technique was followed in

\section{Data collection procedures}

The data collection procedures are divided into three parts such as development of questionnaire, participation selection and collection of specific data.

\section{Development of questionnaire}

According to research questions and objectives of study variables were selected first. An interviewer questionnaire was developed in Bengali in such a way that all variables could be obtained in to account categorically. After developed the questionnaire pre-test was done among the senior staff nurses in similar settings of other hospital which was excluded from the study population. Model of questionnaire is enclosed in the annexure.

\section{Participant selection}

The investigator was briefed objectives, benefits, risks and burdens of the study to the senior staff nurses. Only positive respondents were selected as research participants constant with the selection criteria. The researcher was taken written informed consent from each of the participants. In the first phase the 
researcher collected general information following the questionnaire.

\section{Collection of specific data}

The data were collected by semi-structured self-administered questionnaire.

\section{Ethical issues}

- An approval was obtained from PH department of LU.

- Permission was obtained from Hospital Director and Nursing Superintendent for data collection from the nurses at Sylhet MAG Osmani Medical College Hospital. Informed consent was taken from the subject.

- The collected data was used for research study maintaining confidentialities and hoping it will not be harmful in their lives.

\section{STATISTICAL ANALYSIS}

The data were entered in a statistical software package of SPSS version 17 (SPSS Chicago IL. USA) for appropriate analysis and interpretation. Values were expressed as frequencies and percentages. Fisher exact test was carried out to explore the relationship between knowledge about prevention and control of hypertension and socio-economic status of the respondents.

\section{RESULTS}

- Socio-economic status of the respondents

- Knowledge on diagnosis and history of hypertension among relatives

- Knowledge on hypertension as a genetic, as a disease, types of hypertension and essential hypertension:

- Knowledge about the causes of essential hypertension, secondary hypertension and the problems of uncontrolled hypertension

- Knowledge about the personal factors, caused by food and grade of hypertension Knowledge about the control and preventive measures of hypertension

- Distribution of the respondents by age and knowledge on control of hypertension

- Distribution of the respondents by age and Knowledge about the preventive measures of hypertension

- Distribution of the respondents by professional qualification and Knowledge about the causes of essential hypertension

Table-1: Socio-economic status of the respondents $(n=150)$

\begin{tabular}{|l|c|c|}
\hline Name of variable & Frequency & Percentage (\%) \\
\hline Sex & 03 & 2.0 \\
Male & 147 & 98 \\
Female & 01 & \\
\hline Age & 63 & 0.7 \\
$<25$ & 77 & 42.0 \\
$25-35$ & 9 & 51.3 \\
$35-45$ & & 6.0 \\
$>45$ & 112 & 74.7 \\
\hline Education & 26 & 17.3 \\
SSC & 11 & 7.3 \\
HSC & 01 & 0.7 \\
Degree & & \\
Masters & 131 & 87.3 \\
\hline Professional education & 16 & 10.7 \\
Diploma in Nursing & 03 & 2.0 \\
BSC Nursing & & \\
MPH & & \\
\hline
\end{tabular}

The above table shows the distribution of the respondents by sex, age, education and professional education. The majority $98 \%$ of the respondents were female and only $2 \%$ were male. The maximum age of the respondents was 51 years and the minimum age was 25 years. The maximum respondents $51.3 \% \quad(n=77)$ were in 35-45 age group. The mean age of the respondents was $37.39 \pm 5.24$ years. The majority had SSC $74.7 \%(n=112)$. and HSC, Degree and masters were $17.3 \%(26), 7.3 \%(n=11)$ and $0.7 \%(n=01)$ respectively. Majority $87 \%(n=131)$ were Diploma in nursing $\mathrm{f}, 10.7 \%(\mathrm{n}=16)$ were BSC nursing and only $2 \%(n=3)$ were MPH holders. 
Table-2: Knowledge on diagnosis and history of hypertension among relatives $(\mathrm{n}=150)$

\begin{tabular}{|l|c|c|}
\hline Name of variable & Frequency & Percentage (\%) \\
\hline Diagnosis of hypertension & & \\
MBBS Doctors & 125 & 83.3 \\
Specialist Doctor & 25 & 16.7 \\
General Doctor & 00 & 00 \\
Medicine seller & 00 & 00 \\
Nurse & 00 & 00 \\
Pharmacist & 00 & 00 \\
Other & 00 & 00 \\
\hline HTN among relatives & & \\
Nil & 100 & 66.6 \\
Father & 14 & 9.3 \\
Mother & 21 & 14.0 \\
Brother & 5 & 3.3 \\
Sister & 6 & 4.0 \\
Uncle & 01 & 0.7 \\
Aunt & 01 & 0.7 \\
Maternal uncle & 01 & 0.7 \\
Maternal aunt & 01 & 0.7 \\
\hline
\end{tabular}

The above tables showed that the maximum no. of the respondents $83.3 \%(\mathrm{n}=125)$ told MBBS doctors and the rest $16.7 \%(\mathrm{~N}=25)$ told Specialized doctor. Results also showed that $66.7 \%(n=100)$ of the respondents told that there was no history of hypertension among relatives. $9.3 \%(n=14)$ told that there was a history of hypertension among their fathers, $14.0 \%(\mathrm{n}=21)$ mothers, $3.3 \%(\mathrm{n}=5)$ brothers, $4.0 \%(\mathrm{n}=6)$ sister, $0.7 \%(n=1) \quad$ uncle, $0.7 \%(n=1), \quad 0.7 \%(n=1)$ maternal uncle and $0.7 \%(n=1)$ Maternal aunt respectively.

Table-3: Knowledge on hypertension as a genetic, as a disease, types of hypertension and essential hypertension (n=150)

\begin{tabular}{|l|c|c|}
\hline Name of variable & Frequency & Percentage (\%) \\
\hline Diagnosis of hypertension & & 83.3 \\
MBBS Doctors & 125 & 16.7 \\
Specialist Doctor & 25 & 00 \\
General Doctor & 00 & 00 \\
Medicine seller & 00 & 00 \\
Nurse & 00 & 00 \\
Pharmacist & 00 & 00 \\
Other & 00 & \\
HTN among relatives & & 66.6 \\
Nil & 100 & 9.3 \\
Father & 14 & 14.0 \\
Mother & 21 & 3.3 \\
Brother & 5 & 4.0 \\
Sister & 6 & 0.7 \\
Uncle & 01 & 0.7 \\
Aunt & 01 & 0.7 \\
Maternal uncle & 01 & 0.7 \\
Maternal aunt & 01 & \\
\hline
\end{tabular}

The table shows that majority $98.7 \%(\mathrm{n}=148)$ were responded hypertension was genetic, only $1.3 \%$ $(\mathrm{n}=2)$ responded hypertension was not genetic. Majority $82.0 \%(n=123)$ of the respondents told that it was a disease in blood vessel, $14.6 \%(n=22)$ heart disease and $3.3 \%(n=5)$ brain disease respectively. Knowledge on types of hypertension, 93.33\% (n-150) told Primary \&Secondary hypertension, only $6.66 \%$ told all three types of hypertension. $99.3 \%$ had knowledge about essential hypertension while only .7 had no knowledge about essential hypertension. 
Table-4: Knowledge about the causes of essential hypertension $(n=150)$

\begin{tabular}{|c|c|c|}
\hline Causes & Frequency & Percentage \\
\hline Genetic, smoking, Diabetes, Kidney disease, \&overweight & 11 & 7.33 \\
\hline $\begin{array}{l}\text { Genetic, smoking, Diabetes, Kidney disease, \&overweight, High intake of fat } \\
\text { containing diet, physical inactivity \& anxieties }\end{array}$ & 21 & 14 \\
\hline $\begin{array}{l}\text { Genetic, smoking, Diabetes, Smoking, Kidney disease, overweight, High intake of fat } \\
\text { containing diet, physical inactivity, anxieties, excess salt intake, }\end{array}$ & 11 & 7.33 \\
\hline $\begin{array}{l}\text { Genetic, smoking, Diabetes, Smoking, Kidney disease, overweight, High intake of fat } \\
\text { containing diet, physical inactivity, anxieties, excess salt intake, Drug addition }\end{array}$ & 74 & 49.33 \\
\hline $\begin{array}{l}\text { Genetic, smoking, Diabetes, Smoking, Kidney disease, overweight } \\
\text { High intake of fat containing diet, physical inactivity, anxieties }\end{array}$ & 12 & 8 \\
\hline $\begin{array}{l}\text { Genetic, smoking, Diabetes, Smoking, Kidney disease, overweight, High intake of fat } \\
\text { containing diet, anxieties, excess salt intake }\end{array}$ & 21 & 14 \\
\hline Total & 150 & 100.0 \\
\hline
\end{tabular}

Majority (49.33\%) of the respondents told Genetic, smoking, Diabetes, Smoking, Kidney disease, overweight, High intake of fat containing diet, physical inactivity, anxieties, excess salt intake, Drug addiction were the causes of hypertension

Table-5: Knowledge about the personal factors, caused by food and grade of hypertension $(\mathbf{n}=150)$

\begin{tabular}{|c|c|c|}
\hline Name of variable & Frequency & Percentage (\%) \\
\hline $\begin{array}{c}\text { Personal factor } \\
\text { Genetic, smoking, Diabetes, anxieties, excess salt intake, overweight } \\
\text { Smoking, Kidney disease, overweight, High intake of fat containing diet, } \\
\text { physical inactivity }\end{array}$ & 147 & 98.0 \\
anxieties, excess salt intake, Drug addition & 02 & 0.7 \\
\hline Caused by food & 121 & 80.6 \\
Smoking, excess salt intake, overweight & 10 & 6.7 \\
Smoking, overweight, High intake of fat containing diet, physical inactivity \\
Excess salt intake, Drug addition & 19 & 12.7 \\
\hline $\begin{array}{c}\text { Grade of HTN } \\
\text { G-1Mild (140-159/90-99) G-2 Moderate (160-170/100-109), }\end{array}$ & 143 & 95.33 \\
Mild (140-159/90-99), Moderate (160-170/100-109), Severe G- & 07 & 4.66 \\
\hline 3(>=180/>=110) & 150 & 100 \\
\hline
\end{tabular}

The above table shows the distribution of the respondents by Knowledge about the personal factors, caused by food and grade of HTN. Results show $98.0 \%$ told Genetic, smoking, Diabetes, anxieties, excess salt intake and overweight were the personal factors caused by HTN. $80.6 \%$ told that Smoking, excess salt intake, overweight were the food caused hypertension. Knowledge about the grade of hypertension was found that $95.33 \%$ told grade-1 and grade- 2 hypertension and only $4.66 \%$ had known all three types of hypertension.

\section{DISCUSSION}

This research work was a descriptive type of cross-sectional study performed on the senior staff nurses of Sylhet MAG Osmani Medical College Hospital during from September 2018 to December 2018 to assess the level of knowledge about prevention and control of hypertension among senior staff nurses. The research participants were recruited from study population consecutively on the basis of defined selection criteria. There was limitations of time and others constrains sample size of the study was limited to 150 in this study. The data collection procedures are divided into three parts such as development of questionnaire, participation selection and collection of specific data. The data were collected by semistructured self-administered questionnaire. The data were analyzed using statistical software package of SPSS version 17 (SPSS Chicago IL. USA) for appropriate analysis and interpretation.

The study revealed that the majority $98 \%$ of the respondents were female and only $2 \%$ were male. The maximum age of the respondents was 51 years and the minimum age was 25 years. The maximum respondents $77(51.33 \%)$ were in $35-45$ age group. The mean age of the respondents was $37.39 \pm 5.24$ years. The educational qualification revealed that the majority had SSC (74.7\%). and HSC, Degree and masters were $17.3 \%, 7.3 \%$ and $.7 \%$ respectively. 
The professional qualifications of the respondents found that $131(87 \%)$ were Diploma in nursing and Diploma in midwifery, $10.7 \%$ were BSC nursing and only $2 \%$ were MPH holders. The maximum no. of the respondents $125(83.3 \%)$ told MBBS doctors and the rest $25(16.7 \%)$ told Specialized doctor diagnose hypertension. The study also found the history of hypertension among relatives. The maximum numbers $100(66.7 \%)$ of the respondents told that there was no history of hypertension among relatives. $12 \%$ told that there was a history of hypertension among their mothers, $7.3 \%$ told the history of hypertension among their fathers. Sisters $3.3 \%$, Brothers $2.7 \%$ and uncles were only.7\%. There were also multiple responses but it was very few. The majority $98.7 \%$ were responded hypertension was genetic, only $1.3 \%$ told hypertension was not genetic. A similar finding found in the study that hypertension share genetic predisposition, medical risk factors and environmental influences [21].

The majority $(81.3 \%)$ of the respondents told that it was a disease in blood vessel, $14.7 \%$ told it was a heart disease and only $3.3 \%$ told that it was a Brain disease.

Hypertension was classified as: Primary or essential hypertension, Secondary or known cause hypertension, Tertiary hypertension. Knowledge on types of hypertension found in the study that $19.33 \%$ had good knowledge, $74.66 \%$ had average knowledge and only $6 \%$ had poor knowledge. Knowledge on essential hypertension was found in the study that 99.35 had knowledge about essential hypertension while only $.7 \%$ had no knowledge about hypertension.

Knowledge about the causes of essential hypertension was relatively high because $98.7 \%$ had good knowledge, .7\% had average knowledge and only. $7 \%$ had poor knowledge.

Knowledge about the causes of secondary hypertension found in the study that $1.3 \%$ had good knowledge, $14.7 \%$ had average knowledge and only $84 \%$ had poor knowledge.

Knowledge regarding problems caused by uncontrolled hypertension was found the present study that $93.3 \%$ had good knowledge, 5.3\% had average knowledge and only $1.3 \%$ had poor knowledge. Knowledge regarding personal factors of hypertension revealed in the study that $98.0 \%$ had good knowledge, $1.3 \%$ had average knowledge and only $.7 \%$ had poor knowledge. Knowledge about the control and preventive measures of hypertension showed in the study that $99.3 \%(n=149)$ had told avoid excess intake of salt and sugar, exercise, control body weight, change food habit, medication and stop smoking were the control measures of HTN.65.3\% told increase intake of vegetables and fruits were the preventive measures of HTN. A similar finding was found in a study conducted by S.L, Drake ${ }^{20}$ that sodium can be found in increasing hypertension.

In the present study it was found that there was no association between age of the respondents and knowledge about control of hypertension. ( $p$ value> $.05)$. The insignificant association was found between age of the respondents and knowledge about preventive measures of hypertension ( $\mathrm{p}$ value $>.05$ ).

The relation between professional qualification and Knowledge about the causes of essential hypertension was also statistically insignificant. ( $p$ value $>$.05). In a study conducted by da Silva SS, Colosimo FC, Pierin AM [33] in Barisal, Bangladesh to assess nursing team knowledge on hypertension and treatment before and after educational intervention. The study found that there was significant relationship between knowledge and education. This finding was inconsistent with present study.

\section{CONCLUSION}

On the basis of this cross-sectional study the following conclusion may be drawn. Knowledge about the history of hypertension among relatives was found that there was no history of hypertension among relatives among the respondents was found only $12 \%$. The majority $98.7 \%$ were responded hypertension was genetic, only $1.3 \%$ told hypertension was not genetic. The majority $(81.3 \%)$ of the respondents told that it was a disease in blood vessel. Hypertension was classified as: Primary or essential hypertension, Secondary or known cause hypertension, Tertiary hypertension. Knowledge on types of hypertension found in the study that $19.33 \%$ had good knowledge, $74.66 \%$ had average knowledge and only $6 \%$ had poor knowledge. Knowledge on essential hypertension was found in the study that 99.35 had knowledge about essential hypertension. Knowledge about the causes of essential hypertension was relatively high because $98.7 \%$ had good knowledge.

The insufficient knowledge about the causes of secondary hypertension found in the study that only $1.3 \%$ had good knowledge.

Knowledge regarding problems caused by uncontrolled hypertension was found that $93.3 \%$ had good knowledge. Knowledge regarding personal factors of hypertension revealed in the study that $98.0 \%$ had good knowledge. Knowledge about preventive measures of hypertension found in the study was relatively insufficient, only $30.7 \%$ had good knowledge. Knowledge about the control measures of hypertension among the respondents was found that only $99.3 \%$ had good knowledge. In the present study it was found that there was no association between age of the respondents and knowledge about control of hypertension. ( $\mathrm{p}$ value> $.05)$. The insignificant association was found between age of the respondents and knowledge about preventive 
measures of hypertension. ( $\mathrm{p}$ value> .05) The relation between professional qualification and Knowledge about the causes of essential hypertension was also statistically insignificant ( $\mathrm{p}$ value> .05).

\section{RECOMMENDATIONS}

From the findings of the present study, the following recommendations can be suggested:

- Since the insufficient knowledge about the causes of secondary hypertension found in the study that only $1.3 \%$ had good knowledge. So in service training should be conducted on non-communicable diseases including hypertension to increase knowledge among the senior staff nurses.

- Knowledge on preventive measures of hypertension was very poor only $30.7 \%$, so it was recommended that sufficient education about preventive measures of hypertension should be provided among the senior staff nurses.

- Workshop, seminar should be organized on hypertension and its preventive and control measures to increase the knowledge level of senior staff nurses.

\section{REFERENCES}

1. Dodu, S.R.A. (1988). Emergence of cardiovascular diseases in developing countries. Cardiology.

2. Nissinen, A., Bothig, S., Granroth, H., Lopez, A.D. (1988). Hypertension in developing countries. World Health Stat Q.

3. Collins, R., Peto, R., MacMahon, S., Hebert, B., Fiebach, N.H., Eberlein, K.A., Godwin, J., Qizilbash, N., Taylor, J.O., Henneckens, C.H. (1990). Blood pressure, stroke, and coronary heart disease, II: short-term reductions in blood pressure: overview of randomised drug trials in their epidemiological context. Lancet.

4. Cutler, J.A. (1993). Combinations of lifestyle modification and drug treatment in management of mild-moderate hypertension: a review of randomised clinical trials. Clin Exp Hypertens.

5. WHO Expert Committee. (1996). Hypertension Control. WHO Technical Report Series No 862. Geneva, Switzerland: World Health Organization.

6. Becker, M.H. (1974). The Health Belief Model and Personal Health Behavior. Thorofare, NJ: Slack.

7. Bovet, P., Shamlaye, C., Paccaud, F. (1996). Epidemiologic transition to chronic diseases and community-based program of prevention of CVD in Seychelles (Indian Ocean). Cardiol Update.

8. Stressor, T. (1992). Equal blood pressure levels carry different risks in different risk factor combinations. J Hum Hypertens.

9. Etymology: Gk, hyper + L, tendere, to stretch

10. Chobanian, A.V., Bakris, G.L., Black, H.R. (2003). "Seventh report of the Joint National Committee on Prevention, Detection, Evaluation, and Treatment of High Blood Pressure.” Hypertension, 42(6).
11. Sagnella, G.A., Swift, P.A. (2006). "The Renal Epithelial Sodium Channel: Genetic Heterogeneity and Implications for the Treatment of High Blood Pressure". Current Pharmaceutical Design, 12(14).

12. Anderson, Douglas, M. (2003). Mosby's Medical, Nursing, and Allied Health Dictionary, 6th edition. St. Louis, MO: Mosby, Worthington-Roberts.

13. Saha, Ms., Sana, N.K., Shaha, R.K. (2006). Serumlipid profile of hypertensive patients in the northern region of Bangladesh. Journal of Biological Science.

14. Frier, B.M., Fisher, M., Diabetes mellitus. (2006). Davidson's Principal and practice of Medicine, Boon NA,Colledge NR, Walker BReds. $20^{\text {th }}$ edition, Churchill Livingstone, Elsevier.

15. Oakeshott, P., Kerry, S., Austin, A., \& Cappuccio, F. (2003). Is there a role for nurse-led blood pressure management in primary care? Family Practice.

16. Aubert, L., Bovet, P., Gervasoni, J. P., Rwebogora, A., Waeber, B., \& Paccaud, F. (1998). Knowledge, attitudes, and practices on hypertension in a country in epidemiological transition. Hypertension, 31(5), 1136-1145.

17. Peters, R. M., Aroian, K. J., \& Flack, J. M. (2006). African American culture and hypertension prevention. Western Journal of Nursing Research, 28(7), 831-854.

18. Zhao, Y., Liu, X., Liu, Y., Jin, J., Yang, J., Zhang, Y. Control of hypertension among rural adult residents in Ningxia, Ningxia Medical University, Yinchuan 750004, China.

19. Drake, S. L., Lopetcharat, K., \& Drake, M. A. (2011). Salty taste in dairy foods: Can we reduce the salt?. Journal of Dairy Science, 94(2), 636-645.

20. Gerber, J. C., \& Stewart, D. L. (1998). Prevention and control of hypertension and diabetes in an underserved population through community outreach and disease management: a plan of action. Journal of the Association for Academic Minority Physicians: the official publication of the Association for Academic Minority Physicians, 9(3), 48-52.

21. Kannel, W. B. (1996). Blood pressure as a cardiovascular risk factor: prevention and treatment. Jama, 275(20), 1571-1576.

22. Peterson, J. C., Adler, S., Burkart, J. M., Greene, T., Hebert, L. A., Hunsicker, L. G., ... \& Modification of Diet in Renal Disease (MDRD) Study Group*. (1995). Blood pressure control, proteinuria, and the progression of renal disease: the Modification of Diet in Renal Disease Study. Annals of internal medicine, 123(10), 754762.

23. Poręba, R., Gać, P., Poręba, M., AntonowiczJuchniewicz, J., Andrzejak, R. Department of Internal Medicine, Occupational Diseases and Hypertension, Wroclaw Medical University, Pasteur 4, PL 50-367 Wrocław, Poland, Relationship between occupational exposure to 
lead and local arterial stiffness and left ventricular diastolic function in individuals with arterial hypertension.

24. Tayo, B. O., Luke, A., McKenzie, C. A., Kramer, H., Cao, G., Durazo-Arvizu, R., ... \& Cooper, R. S. (2012). Patterns of sodium and potassium excretion and blood pressure in the African Diaspora. Journal of human hypertension, 26(5), 315-324.

25. Haque, M. M., \& Nasreen, S. A. (2008). Epidemiological study of risk factors of stroke and its immediate consequence. Mymensingh Medical Journal: $M M J, 17(2), 124-128$.

26. Chen, Y., Factor-Litvak, P., Howe, G. R., Parvez, F., \& Ahsan, H. (2006). Nutritional influence on risk of high blood pressure in Bangladesh: a population-based cross-sectional study. The American journal of clinical nutrition, 84(5), 12241232.

27. Rahman, M., Tondel, M., Ahmad, S. A., Chowdhury, I. A., Faruquee, M. H., \& Axelson, O. (1999). Hypertension and arsenic exposure in Bangladesh. Hypertension, 33(1), 74-78.

28. Yoon, S. S. (2010). Recent trends in the prevalence of high blood pressure and its treatment and control, 1999-2008 (No. 48). US Department of Health and Human Services Centers for Disease Control and Prevention, National Center for Health Statistics.
29. National Center for Health Statistics (US). (2010). Health, United States, 2009: In Brief (No. 2010). US Department of Health and Human Services, Centers for Disease Control and Prevention, National Center for Health Statistics.

30. US Department of Health and Human Services. (2000). Healthy people 2010: with understanding and improving health and objectives for improving health. 2nd ed. 2 vols. Washington, DC: US Government Printing Office.

31. CDC. (2009). National Health and Nutrition Examination Survey (NHANES): health tech/blood pressure procedures manual. Hyattsville, MD: US Department of Health and Human Services, CDC, National Center for Health Statistics.

32. Miller, R.G. (1977). Developments in multiple comparisons.

33. Egan, B.M., Zhao, Y., Axon, R.N. (2010). US trends in prevalence, awareness, treatment, and control of hypertension, 1988--2008. JAMA.

34. Bibbins-Domingo, K., Chertow, G., Coxson, P. (2010). Projected effect of dietary salt reductions on future cardiovascular disease.

35. Institute of Medicine. (2004). Dietary reference intakes for water, potassium, sodium, chloride, and sulfate. Washington, DC: The National Academies Press. 